\title{
STRATEGIC OPTIONS FOR SUSTAINABLE LANDFILLING AND LEACHATE TREATMENT - A SURVEY AND DISCUSSION OF STATE-OF-THE-ART IN SWEDEN
}

\author{
Staffan Agren \\ The Ragnar Sellberg Foundation, Sweden
}

\begin{abstract}
Even if landfilling has become the least prioritised waste option, it cannot be neglected since it will likely last many decades ahead. The potential environmental impact of old as well as new landfills will remain even longer and has to be considered from a sustainability point of view in the sense that future generations shall not inherit environmental problems because of today's landfilling. The choice of leachate treatment contributes in this respect. Five landfilling strategies may be focused in terms of sustainability: instant containment, storage under water, flushing, aerobic on-site stabilisation, and landfill mining. They rely on methods like co-treatment with sewage, or different setups of nature-like or more advanced treatment systems. Though solutions seldom are perfect, it is likely that we still can develop better and more consistent strategies and methods, promoting consensus on how to move forwards. For a rational choice, it is very important to compare the outcome of all landfilling strategies and leachate treatment methods by estimating benefits and costs of different options. This includes consideration of the cost of various environmental effects and resource depletion, as well as of different measures for environmental protection, remediation and resource conservation. The result is an estimation of the contribution to the environmental debt burden that has to be eliminated to fulfil sustainability. The alternative with the best net outcome in this direction shall be chosen. Much of the knowledge for such calculations, in terms of modelling, input data, and evaluation criteria, is however insufficient or subject to disagreement. That is why it is easy to question the Swedish policy of treating leachates in local systems instead of in sewage works. A proposal to enable the funding of basal remaining research tasks is to create large PPP (Private Public Partnership) formations, aiming at identification of optimal overall strategies and method combinations for landfilling and leachate treatment.
\end{abstract}

\section{INTRODUCTION}

To encourage effective resource use, the European Waste Hierarchy primarily endorses waste minimisation, and, in order of priority, re-use, material recovery and energy recovery of wastes still generated. The deliberate consequence will be less landfilling. The insight of the need of such a principal shift in waste management is spreading in 
more and more countries. On the other hand, old structures and habits will pronouncedly prolong the time for realisation of this new waste paradigm. Although a change may be well motivated, we have to accept that landfilling will be a widespread option in the world during decades ahead.

Either talking about closed, landfills in operation or future landfills, they all have the potential of a long-lasting environmental, economic and social impact that cannot be neglected. Figure 1 shows that the possible environmental impact of the substance $\mathbf{x}$ in a municipal landfill may last for centuries. Based on simple extrapolation and with today's concentration in the leachate, it would take in the order of hundreds of thousands of years for a studied landfill to empty its cadmium content [2]. All organic matter might be degraded after several hundred years or several hundreds of thousands of years, depending on the different conditions that might influence a $10 \mathrm{~m}$ deep landfill [3].

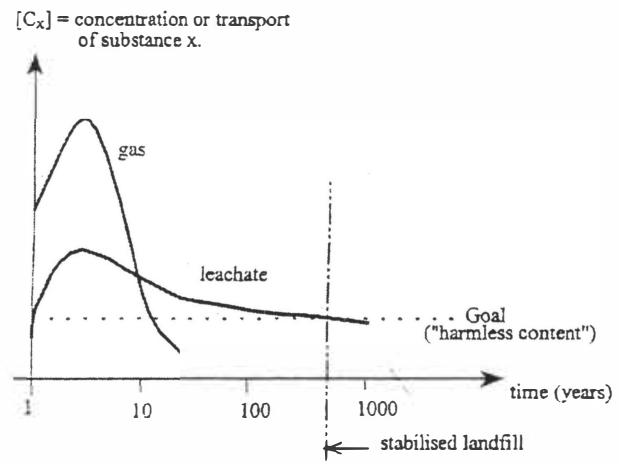

Figure 1: Overview of timescale for outflow and emission potential for a municipal landfill. [1]. This timescale may be extended to hundreds of thousands of years, depending on different conditions.

Besides the emission of methane gas, the potential environmental impact of municipal landfills is associated with the internal generation of leachate, being rainwater that passes through the waste and washes out different salts and contaminants. The environmentally most problematic substances in the leachate are ammonium nitrogen, heavy metals, sodium chloride, and organic substances including a large number of man-made and often persistent organic pollutants [4] that tend to be seriously toxic and accumulate in biota.

The content of a leachate reflects the composition of the landfilled wastes but also their dominating degradation phase [5]. On top of the wide variety of materials and substances in landfills, one can add a slow chemical transition towards a refractory humic fraction among the organic substances [6], the additional transport of contaminants on the surface of colloidal matter [7], and the occurrence of preferential flow paths favoured by the heterogeneity of the wastes [8]. This complex situation makes the task of understanding and predicting the environmental impact of landfills and leachates extremely difficult, not least for the time after closure and capping [9]. 
KALMAR ECO-TECH'03

Bioremediation and Leachate Treatment

KALMAR, SWEDEN, November 25-27, 2003

The long-term fate of contaminants in landfills is a multi-dimensional question. Considering the relatively low concentration of metals in many leachates, and estimated amounts of metals deposited in landfills [2], it seems that under anaerobic conditions most metals and strongly hydrophobic organic substances [8] are immobilised. This could be as precipitates, or directly adsorbed on the surface of the original wastes or their secondary products (mainly metal hydroxides, metal sulphides, metal carbonates or metal-organic compounds).

On the other hand, experiments show that under aerobic conditions substantial amounts of metals may become mobilised whenever oxygen and water start flowing into the waste body again [10]. Theoretical scenarios have been created [9], but predictive modelling is hampered by the shortage of reliable input data, the complex set of parameters, and the long time involved.

Recently, old waste materials were sampled from a depth of down to $18 \mathrm{~m}$ in the 38-year old landfill at Högbytorp $[10,11]$, Stockholm, Sweden. The purpose was to study metal mobilisation under certain changes of the landfill conditions. This will give some of the hard data needed for improved modelling of the processes that decide the long-term environmental performance of closed landfills.

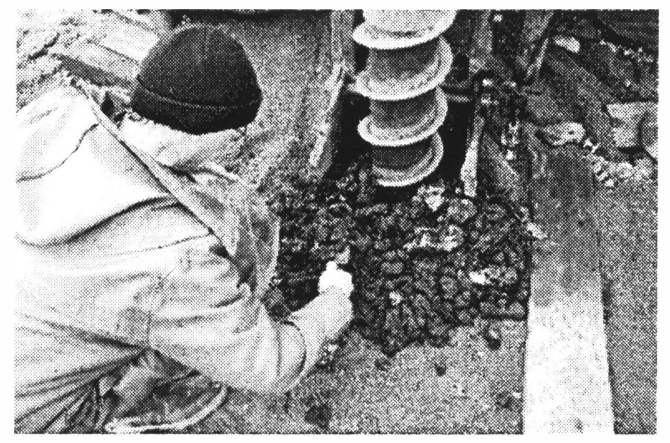

Picture 1: A drilling machine takes up old waste materials from different depth levels (the picture is from the Högbytorp landfill, Stockholm, Sweden).

Better understanding of landfill processes means knowing more about the origin of leachates, which makes it easier to choose the right leachate treatment in different cases. Principally, there are nearly 20 biological, chemical or physical methods that can be applied on leachates. Commonly, two or more methods have to be combined to give the desired effect.

The aim of this paper is to survey possible strategic options for landfilling from a sustainability point of view, and to elucidate in general terms the applicability of different methods for leachate treatment in this respect. 
KALMAR ECO-TECH'03

Bioremediation and Leachate Treatment

KALMAR, SWEDEN, November 25-27, 2003

\section{SUSTAINABLE LANDFILLING AND LEACHATE TREATMENT}

Choices that seem all right from the landfill operator's perspective do not per definition correspond to what is best from society's point of view. For the protection of the environment as a limited resource of fixed capital, one has to weigh in items and values that go beyond the time-horizon and scope of quarterly profit and loss reports. The typical long-term character of most environmental issues is best brought to light by applying the sustainability concept. This is the reason why sustainability is and has to be one of the main goals for green policies in Europe as well as at the global level.

Basically, sustainable landfilling depends on a sustainable waste management perspective. This implies that only wastes shall be landfilled that society still cannot motivate for re-use or recovery because of economic, technological or environmental reasons. Moreover, landfilling shall be done in a way that simplifies later recovery. The purpose in this survey is however to delimit the perspective to the more direct and narrow application of the sustainability concept: future generations shall not inherit environmental problems because of today's landfilling, or shall not increase the environmental debt burden of future generations. That is how well-managed leachate treatment can contribute to sustainability as well.

The more precise meaning is that the aim in landfilling, and thus in leachate treatment, must be to prevent liberation of substances enriched or produced in the technosphere, which systematically accumulate in nature and significantly harm humans and ecosystems. This includes all transporting and processing effects on the environment as well as the consumption of different resources.

\section{LEACHATE TREATMENT IN SWEDEN}

In the year 2001, there were 227 municipal landfills in Sweden, accounting for those receiving more than 50 tonnes of waste [12]. Among these, 7 landfills received more than 100,000 tonnes, together managing about $30 \%$ of the landfilled wastes in Sweden. In total, there was a production of 11 million cubic metres of leachate. 75 plants collected landfill gas as well.

Most Swedish landfills are owned and managed by municipal companies. There are only two large private landfill operators in Sweden, Ragn-Sells and Sita. The number of Swedish landfills has slowly decreased during the years, and will soon decline much faster because of the imperative demands and economic implications of the EU Directive on landfilling of waste [13], and the landfill tax introduced in the year 2000. Only large plants have the economic marginal to handle constantly increasing costs. In addition, many are situated at places where they cannot meet the leakage limits specified for the new three safety classes of European landfills for hazardous, moderately hazardous, and inert wastes, respectively.

\subsection{Retrospect}

Not until the seventies, Sweden became aware of the environmental necessity of treating leachates instead of just letting them out in the nearest watercourse or lake. By that time, 
many sewage works were already built in Sweden. During many years, state-of-the-art for the Swedish landfills was to send non-treated leachate to such plants, since this was the simplest solution.

In the nineties, a new discussion emerged that the processes in sewage treatments plants were not fit for treating industrial waters and leachates, especially not if the proportion of such input was large. Proven or not, the decisive argument was that heavy metals and organic toxicants left after treatment made the recycling to agricultural land of phosphorous and other nutrients in sewage sludge undesirable. This gave rise to an unholy political alliance between agricultural/agrofood-related businesses and sewage plant owners in favour of changing state-of-the-art from co-treatment with sewage to local treatment at the landfill sites. In consequence, landfill operators were encouraged to start investing in local treatment systems for leachates.

\subsection{Local leachate treatment}

Among the 227 Swedish landfills addressed here, 144 had invested in local leachate treatment in 2001. On the other hand, that same year Swedish sewage works still took care of 7 million cubic metres of leachate, corresponding to nearly $2 / 3$ of the total collected volume.

The most widespread methods for local leachate treatment are listed in Table 1. The category Others includes a biocell, a bio-treatment basin, addition of hydrochloric acid, a sand filter, an evaporation tower, and an unspecified pilot plant. Reverse osmosis, UVlight and activated carbon are methods not yet introduced in regular treatment systems in Sweden.

Table 1: The number of full-scale plants in Sweden that apply different methods for local leachate treatment (in order of usualness). Figures are taken from [12] and valid for the year 2001.

\begin{tabular}{|ll|}
\hline Type of treatment & Plants \\
\hline Aeration & 84 \\
Irrigation of soil-plant & \\
system & 36 \\
Infiltration & 35 \\
Recirculation & 31 \\
Soil beds & 16 \\
Vegetation filter & 15 \\
Chemical precipitation & 6 \\
Mechanical treatment & 4 \\
Biological batch reactor & \\
(SBR) & 4 \\
Wetlands & 3 \\
Others (single cases) & 9 \\
\hline
\end{tabular}




\section{LANDFILLING STRATEGIES AND SUSTAINABILITY}

Sweden is obliged to adapt a landfilling strategy in compliance with the EU directive on landfilling of wastes [13]. This does not hinder a discussion whether this strategy really fulfils sustainability, or if some other strategy should be preferred or used in combination.

\subsection{Instant containment}

A short description of current state-of-the-art of landfilling in Sweden is gas collection and leachate treatment during the active phase, final capping with an impermeable cover to prevent further leachate production during the passive phase, and a general obligation of after-care and control during 30 years after closure. Also municipal landfills have to be bottom-sealed with some kind of geomembrane on a bed of natural or added clay soil. Old and new landfills must be situated at geologically favourable places where the soil significantly delays and dilutes all effluents. This can be summarised as an instantcontainment strategy, aiming at elimination of the long-term impact of landfills by keeping the wastes shut in.

New laws are coming that will prohibit landfilling of organic materials in order to minimise settlements that pose a threat on the durability of the capping after closure and take away the source of emissions of greenhouse gases from landfills. However, when formulating sustainable strategies it must be considered that existing municipal landfills nevertheless contain a lot of organic matter. Even ashes after incineration may to a significant extent contain such a fraction.

It is important to recognise water as one of the key factors controlling leachate quality. As the liquid-to-solid ratio (L/S ratio) increases, the concentrations of different substances in the leachate become reduced. The L/S ratio needed to reach "final storage quality" depends on the substance and the specific discharge limit. According to Kylefors \& Lagerkvist [5], the minimum L/S ratio needed for most substances is just below 10 . Assuming a normal Swedish landfill with 10 meters of filling height and a filling time of 20 years, the L/S ratio achieved at the time of closure is between 1 and 2 . When the allowed volume of a landfill is fully utilized, the landfill will be capped with a lowpermeability cover. Gradually anaerobic degradation will be inhibited due to lack of water, thus gas production will cease, as will leachate production. Any leachate still generated will stay very high in ammonia, salts and organic substances.

The European Directive on landfilling of waste [13], and as a consequence Swedish law, prescribes a maximum penetration of 50 litres per year and $\mathrm{m}^{2}$ land surface for closed municipal landfills, which in Sweden normally correspond to so-called class 2 landfills. In general, this corresponds to an increase of the L/S ratio of tless than 0.01 per year, and stabilisation will take very long time. Thus, capping a landfill with an impermeable membrane while it still contains most of its original contaminants means that many future generations will be exposed to most of the landfill's potential environmental impact. This makes the quality of the membrane a key issue. 
The instant-containment strategy may probably work during the 30 years when the landfill owner at the minimum is responsible for post-closure management (note that, $e$. $g$., in the Netherlands this responsibility is unlimited). Later generations may however forget where the landfill is situated. The main objection is that, due to unavoidable ageing of the plastic liners [16] as well as delayed settlements in the waste material or unforeseeable movements in the geological formation, the barriers will sooner or later become impaired. This will cause renewed production of leachate and gas, and an impact that may exceed acceptable environmental levels. In the light of this perspective and the relatively short transport time allowed to the nearest recipient ( $>50$ years as mentioned), it is easy to question whether the instant-containment strategy really guarantees sustainability in a strict sense [16].

\subsection{In preparation of containment}

Direct measures can be taken to better prepare the landfill for containment after closure. Leikam \& Stegmann suggest mechanical-biological pre-treatment of wastes before landfilling [14]. The short-term effect is saved filling space and reduced gas production in the anaerobic landfill. After capping there will be decreased settlements, i.e. less risk of or delayed barrier malfunction, and a smaller amount of pollutants left. This pretreatment is rarely used in Sweden.

An alternative is recirculation of leachate to accelerate waste degradation in the landfill body itself [15]. This decreases the volume of leachate necessary to treat, and may favour vegetation that helps stabilising the landfill edges. In addition, the internal gas production rises. The final result will be smaller remaining settlements and reduced amounts of biodegradable pollutants in the waste. Recirculation demands not only leachate collection but also some kind of bottom-containment (clay and a geomembrane) and a well built-out gas collection system to avoid significant losses to groundwater and atmosphere. Farreaching recirculation of untreated leachate is considered undesirable because of the possibility that increasing salt concentration causes internal destabilisation of the compacted waste materials, gives an extremely salt leachate, and even becomes toxic to the bacteria wanted for the degradation of the landfilled waste.

\subsection{Storage under water}

A rarely discussed strategy is waste storage under water [3]. This means that the waste is put into a natural or artificial depression, ensuring that it will always be water-saturated (covered by water) under natural conditions (i. e. in a groundwater discharge zone). To avoid problems with short-term fermentation, all easily degradable wastes are preferably removed before storage. A water-saturated system delimits the oxygen supply and favours chemical equilibrium conditions, which results in slow degradation of the organic matter and puts a brake on metal release.

The underlying idea of storage under water is once again to encapsulate the potential environmental impact but to use water itself as a kind of low-permeable containment. However, the depression will sooner or later become filled to the brim and some run off will start, or it will cease to be tight. In the former case, the water must be good enough 
not to cause a delayed leachate problem. In the latter case, the essential water-saturation cannot be maintained any longer. Another objection is of course that no existing landfills are built in prepared depressions, which delimits the applicability of this strategic option to new landfills.

\subsection{Flushing}

Flushing is a strategy that relies on much water. The reason is that deliberate addition of very large volumes of water is a way of speeding up microbial degradation and washing out of salts in order to stabilise landfills and decrease their potential impact [16]e In comparison with instant containment and storage under water, flushing is straightforward in the sense that it aims at direct reduction instead of conservation of the potential contaminants inside the landfill.

To avoid drawbacks, it is recommended to recirculate leachate that has been nitrified as well as denitrified. Walker et al. [17] report that the L/S ratio has to be raised up to 7.5 for good flushing results. However, since their well-fragmented waste material is somewhat idealised, the recommendation of a ratio near 10 seems more credible [5]. After pre-treatment of the waste with mechanical-biological or thermal methods, a ratio of 3.5 may be enough [18].

In general, flushing requires sufficient and cheap enough water supply, hydrological barriers hindering losses to groundwater, well developed monitoring, relatively homogeneous waste materials (preferably shredded and ground materials without daily covering), rather much land area, and a recipient that dilutes inorganic salts to an acceptable extent (preferably the sea). All these condition do not seem possible for many old landfills but can of course be arranged for new ones.

It is easily understood that the treatment cost per cubic metre has very large influence on the cost of flushing, and thus on the choice of treatment measures. A combination of some cheap nature-like system and partial recirculation of the treated leachate would probably offer the best possible cost level as regards the treatment, but the dilemma is that there is little control of the total net outcome when taking the environment into account.

\subsection{Aerobic on-site stabilisation}

Aerobic on-site stabilisation is sometimes referred to as aeration or aerobisation of landfills. Like flushing, it is a strategy that aims at direct elimination instead of conservation of pollutants.

Ritzkowski et al. [19] argue that calculated, controlled and time-limited aeration through a system of air wells significantly improves the emission behaviour of landfills, due to stabilisation and reduced pollutant potential of the waste. Especially organic compounds and inorganic nitrogen pollutants can be significantly removed, but aeration must be well controlled to suppress mobilisation of heavy metals. An exposed geomembrane cap (EGC) can be used to increase the control of the landfill during these measures, as well as for increasing methane gas collection in anaerobic landfills. 
Leikam et al. [20] describe the achievement of a biologically stabilised state by accelerated microbial conversion. After aeration, a well-designed soil cover that is less costly in construction, operation, and maintenance, can replace containment. Bozkurt \& et al. [21] propose a self-sustained soil cover with an organic-rich top layer that supports vegetation and an inorganic layer beneath it, which would be comparable to the common Swedish soil called podzol and favour methane-oxidation in the top layer.

\subsection{Landfill mining}

The most radical strategy for the taking care of a landfill is of course to excavate it. This is another straightforward method from a sustainability point of view. Gösch [22] claims that a critical part is to avoid negative effects on the environment and the workers during the transformation from anaerobic to aerobic conditions. One of the negative effects is definitely odour.

The landfill material becomes size reduced and screened, hazardous wastes are sorted out, visible materials like metal objects are recycled, and combustible materials are taken aside for energy purposes. The remains can be used as filling materials in constructions or in other landfills. Between 20 and $80 \%$ of the excavated waste may be extracted for reuse [23], which may be more developed recovery or simply contributes to the covering of other landfills. Elements of the cost-benefit evaluation of landfill mining are the use of energy, the cost of taking care of the "concentrate" of hazardous substances, and the value of the recycled material fractions. The outcome obviously depends much on the actual content of the landfill in different cases.

Landfill mining is internationally recognised and does not seem to oppose the EU Directive on landfilling of waste, if pollution of groundwater is prevented in the right way. This measure is normally motivated by the need of land for buildings or new landfills. Building houses on covered landfills is disadvantageous, since stabilisation is very bad and pilework solving this problem has to penetrate the top and bottom sealings. This will not only let water in again but also introduce explosion risks due to methane gas. The cost of mining has to be compared with the loss of income for not building saleable houses. In densely populated areas, it is obvious that this type of income may exceed the cost of landfill mining. It must always be possible to dispose of or take care of all the excavated materials somewhere else.

\section{LEACHATE TREATMENT METHODS AND SUSTAINABILITY}

Implementation of strategies depends on methods that fulfil them. Effective treatment methods that can be well enough described in terms of function and performance do not support sustainability per se but are needed to make it possible. The intention here is only to survey and consider common or principally interesting methods in relation to that purpose.

\subsection{Co-treatment with sewage}

The first Swedish sewage plants were built for phosphorous removal to save Swedish lakes from eutrophication. Later on, also nitrogen removal was considered, because the 


\section{KALMAR ECO-TECH'03}

Bioremediation and Leachate Treatment

KALMAR, SWEDEN, November 25-27, 2003

insight grew that the Baltic Sea suffers from eutrophication due to nitrogen excess. Sewage works have low running costs, very good removal effiect on phosphorous and nitrogen, operate continuously, and use well-educated personnel [24].

The latest development of the recycling of sewage sludge to farmers is that it has decreased substantially. New reports about fire retardants and other organic pollutants have come on top of the earlier ones about PCB and heavy metals. Investigations have started to find the best method for phosphorous extraction from sludges before landfilling or incineration, or from the ashes after incineration. An increasing application is composting of sewage sludges with other organic wastes, mixing them with soil materials for use in parks and various construction works, including landfill covers.

If sewage sludge is not accepted in farming any longer, no main argument remains for throwing out leachates from the sewage works. In fact, it is not undisputed that leachates are unsuitable for co-treatment with sewage. Cossu et al. [25] argue that leachates actually improve the efficiency in this respect. The question is if all landfill operators are interested in returning to the traditional option. Making use of the payoff of already builtup local systems may actually be more economical.

Interestingly enough, there seem to be no studies made on what types and amounts of pollutants that sewage works actually let through without treatment effect, how significant such emissions are in comparison with those from other sources, and what local pre-treatment that would be needed to prevent them when making use of sewage works. Such overall considerations are rarely made by decision makers, which shows that there is still much left to improve as regards the ability to evaluate environmental risks and prioritise between protection measures.

\subsection{Nature-like systems}

There is a complex mix of mainly "soft" factors that governs the processes in nature-like systems. Being used for leachate treatment, their performance may well be far from optimum, since much knowledge is missing [26], e. g. about the best choice of Salix clones [27], different operational strategies, the nitrogen budget, the connection between load and result, and long-term aspects like salination or soil degradation/accumulation of toxic substances.

Nature-like treatment-systems are problematic from a regulatory point of view. They tend to miss a clear discharge point, which makes the application of traditional end-of-pipe limits troublesome. In addition, it is difficult to compare nature-like systems with hightech ditto in terms of Best Available Technology (BAT), as required by law in the permit process. This aspect is not least valid in systems deliberately mixing nature-like and hightech treatment methods.

It still remains to fully evaluate all aspects of nature-like treatment systems in order to confirm that they are sustainable. For the landfill operators however, they seem to offer lower running costs in comparison with other systems [24]. Probable reasons are that nature-like systems are good at absorbing nitrogen, the price of land is relatively low in a 
sparsely populated country like Sweden, the necessary technologies are simple, and the input of extra energy can be held rather small. However, the real costs of optimal performance are not well known since insight is lacking in what measures that are necessary to get there, both from operational and environmental points of view. Picture 2 is from a landfill with an irrigated soil-plant system, where research has been done to better understand the efficiency of the leachate uptake by different Salix clones [27].

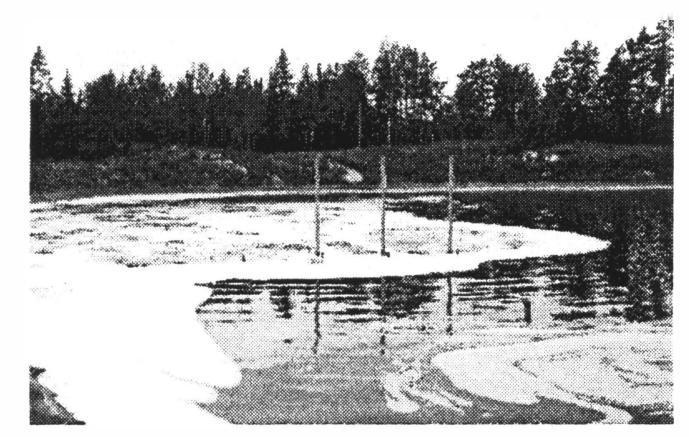

Picture 2: The leachate is subject to potent aeration, nitrogen-reduction and sedimentation before being pumped to irrigated Salix areas nearby (the picture is from the Högbytorp landfill, Stockholm, Sweden).

Wetlands are reported to take care of common wastewaters with good results. There are indications that wetlands also have a good reduction effect on nitrogen and organic toxicants in leachates. Somewhat of an advantage with wetlands over energy crops is that the desired processes are governed by geological factors rather than skill in plant cultivation. For wetlands, the cost of used land is mainly a question of ecological cost.

If irrigation or infiltration of leachate cause accumulation of hazardous substances, the environmental authorities might question whether areas outside the landfill should be used. The only way to establish a positive net outcome of nature-like systems for leachate treatment is more research, and development of tools and measures for improved efficiency and environmental evaluation. Otherwise the authorities may refer to the principle of cautiousness and hesitate to give permits. In that case the landfill operators have to adapt more advanced and expensive systems for the local treatment.

\subsection{More advanced treatment methods}

Chemical precipitation, absorption on activated carbon, ozone, UV-light, addition of hydrochloric acid, and biological batch reactors, are examples of more advanced treatment methods. They offer ways of getting faster and/or improved results for certain purposes but at raised cost [24]e

High-tech methods like reverse osmosis and thermal evaporation separate an especially wide range of pollutants at the same time. On the other hand, these methods also cost 
quite more per cubic meter of leachate. This does not depend only on resources used for equipment and operation but also on the need of complementary actions.

In practice, reverse osmosis has to be combined with some kind of biological treatment like aeration, activated sludge and/or vegetation uptake to reduce most of the nitrogen [28], a major pollutant in municipal leachates. Frequent clogging of the membrane caused by large amounts of particles or colloids may raise the running cost. As concerns thermal evaporation, substantial acidification is necessary to keep the formation of ammonia down [24]. Not least the choice of energy source is crucial for the environmental performance in this case.

Reverse osmosis and thermal evaporation produce retentates that have to be treated as hazardous wastes. They may be put into class 1 landfills, or become incinerated and landfilled. In the latter case, heavy metals will still remain in the ashes. These metals can be extracted for recycling purposes. Alternately, the retentates or the ashes may be landfilled after solidification in concrete made of the bottom ash from coal incineration (contains lime), or buried in tight containers deep down in the bedrock. Whatever the choice is, more costs are added on top of the cost of already expensive methods.

\section{CONCLUSIVE REMARKS AND VIEWPOINTS}

This survey shows that the practical fulfilling of sustainability in landfilling and leachate treatment certainly is no obvious task. Moreover, solutions to improve environmental performance within these areas raise the objection of being typically downstream, aiming at aftercare rather than prevention. Focusing on such solutions is not sustainable in the most far-reaching sense of the concept. However, all measures to limit or even reduce the environmental debt burden of coming generations may be regarded as steps in the right direction.

\subsection{Options and net outcome}

In contrast to instant containment and storage under water, straightforward strategies like flushing, aerobic on-site stabilisation, and landfill mining, seem principally attractive in terms of sustainability. They certainly attack the key issue. If the containment prescribed by the EU Directive on landfilling of wastes aims at ensuring the environmental performance during the passive life phase of landfills, the preparation of this phase by the active application of other strategic options does not seem to violate the Directive.

In practice, the flushing strategy seems applicable either on new landfills, optimally constructed from the very beginning, or on old landfills being excavated. Because of its sensitivity to the treatment cost per cubic metre, flushing will likely depend on naturelike or other relatively cheap treatment systems. Strategies like landfill mining and aerobic on-site stabilisation are usually connected with old landfills but can be complemented with recirculation in a way that creates so-called bioreactors, a solution actually applied on new landfills in USA and Canada.

It has to be noted that every single element of a sustainable strategy must be justified from precisely that point of view. Reports say that flushing and aerobic on-site 
KALMAR ECO-TECH'03

Bioremediation and Leachate Treatment

KALMAR, SWEDEN, November 25-27, 2003

stabilisation reduce most of the nitrogen, and a lot of the organic substances [16, 19 etc.]. Flushing washes out salts as well. Landfill mining "simply" removes all the waste. However, little is told about the least degradable fraction of the organic substances or the heavy metals: what will be left on-site, and will it stay there? If materials are moved away, will this let heavy metals free or demobilise them somewhere else? No cost or impact shall be forgotten in the calculations.

Approval of larger treatment costs [24] opens the door for high-tech methods like reverse osmosis or thermal evaporation. At a glance, these methods seem very effective. Consideration of their real limitations partly modifies this impression. There will, for instance, be a concentrate with metals left. Furthermore, it is evident that even the best treatment of leachate from a methane-producing landfill in operation does not eliminate more than a small amount of all potential pollutants in the waste. This is why these methods cannot be considered sufficient strategic options themselves.

As a matter of fact, sustainability must focus on the whole lifetime of landfills, including the period after closure. This includes accounting for the need of control during extended time periods ahead. Will, e. g., metals remain almost immobilised as in today's municipal landfills, or will changing conditions increase their outflow $[10,11]$ ?

For a rational choice, it is very important to compare the outcome of all landfilling strategies and leachate treatment methods by estimating the whole range of benefits and costs of environmental and traditional economic character. This includes consideration of the cost of various environmental effects and resource depletion, as well as of different measures for environmental protection, remediation and resource conservation. The result is an estimation of the contribution to the environmental debt burden that has to be eliminated to fulfil sustainability. The alternative with the best net outcome in this direction shall be chosen.

\subsection{Need of knowledge}

The strategies and methods described here may be looked upon as questionable compromises, or exaggerated efforts, or deliberate low-cost solutions to easily get rid of recognised problems in connection with landfilling and leachate treatment. The overall problem is that these strategies are not enough investigated and quantified in terms of environmental impact and efficiency, total cost vs. benefit, choice of time perspective etc.

As long as such essential knowledge is lacking, society will not be able to make a rational choice between the different strategic options, methods to realise them, or the research projects needed to find new or improved possibilities. It is likely that we still can develop better and more consistent strategies and methods. The key issue is rather if society will succeed in producing and making use of good knowledge in a way that promotes increased agreement, and even consensus, among the decision makers on what direction and goals that are motivated.

Ideally, thorough knowledge build-up always shall precede the formulation of goals and regulations. Otherwise much financial resources may be spent on wrong and 
KALMAR ECO-TECH'03

Bioremediation and Leachate Treatment

KALMAR, SWEDEN, November 25-27, 2003

counterproductive measures. Though we find reason for more recycling, landfilling still is part of waste management. These insights must be forwarded to the public research funds (the $6^{\text {th }}$ Framework Programme and, in Sweden, Mistra, Nutek, Vinnova, Formas and Naturvårdsverket) to make them recognise that also applied landfill research needs funding to get on the track towards sustainability.

The consequence of too little knowledge is well exemplified by the Swedish experience. The alliance that banned co-treatment with sewage pushed the development towards local treatment systems, although very little is known whether such systems really are better or worse for the environment. Society has given very little support to the landfill operators for understanding of the optimal design and operation of local systems. In reality, investments made in local leachate treatment have neither lead to increased recycling of sewage sludge back to arable land nor established improved sustainability in leachate treatment. The economics of this transition still remains to be analysed.

A crucial objection is that the most important source of pollutants in absorbents like sewage sludge likely is diffuse emissions. Still society permits the use of many questionable substances in products, $e . g$., triclosan in tooth-paste or washing-up detergents. Until recently, cadmium-polluted fertilisers were much used by Swedish farmers. It is an utterly serious shortcoming that society misses adequate knowledge and overall perspectives for well-considered strategies and priorities in this topic area.

\subsection{Improved decision-making}

To support improved decision-making as concerns landfilling and leachate treatment, a proposal is to form a European PPP (Private Public Partnership) group or corresponding national groups to enable the funding of basal remaining research tasks concerning landfills and leachates. The aim should be to identify optimal overall strategies and method combinations that comply with the EU directive on landfilling of waste before its final year of implementation in 2008.

This work should run parallel with intensified implementation of environmental sustainability within waste management and the whole production system. This is the only way to defeat today's disorderly reductionism that lets sustainability drown in thousands of possibilities and details without seeing the connection behind them.

\section{REFERENCES}

[1] Belevi, H. \& Baccini, P. Long-term behavior of municipal solid waste landfills. Waste Management \& Research, 7, p. 43-56, 1989.

DOI: https://doi.org/10.1016/0734-242X(89)90007-4

[2] Aulin, C. \& Neretnieks, I. Material balance for an industrial landfill (Vol. III). Proc. of the $5^{\text {th }}$ Int. Landfill Symposium in Sardinia, eds. T.M. Christensen, R. Cossu \& R. Stegmann, CISA: Cagliari, Italy, pp. 173-180, 1995.

[3] Bozkurt, S., Moreno, L. \& Neretnieks I. Long-term fate of organics in waste deposits and its effect on metal release. The Science of the Total Environment, 228, pp. 135-152, 1999. DOI: https://doi.org/10.1016/S0048-9697(99)00047-9 
[4] Öman, C. \& Hynning, phosphorous. Identification of organic compounds in municipal landfill leachates. Environmental Pollution, 80, pp. 265-271, 1993.

DOI: https://doi.org/10.1016/0269-7491(93)90047-R

[5] Kylefors, K. \& Lagerkvist, A. Changes of leachate quality with degradation phases and time (Vol II). Proc. of the $6^{\text {th }}$ Int. Landfill Symposium in Sardinia, eds. T.M. Christensen, R. Cossu \& R. Stegmann, CISA: Cagliari, Italy, pp. 133-149, 1997.

[6] Agren, S. The possible similarity between organic substances in leachates and forest waters. Proc. of the $3^{\text {rd }}$ Int. Conf. on the Establishment of Cooperation between Companies/Institutions in the Nordic Countries and the Countries in the Baltic Sea Region, eds. W. Hogland \& V. Vyšniauskaite, University of Kalmar and the Swedish Association of Waste Management (RVF Rapport 02:02, RVF:s utvecklingssatsning för deponering): Malmö, pp. 117-125, 2002.

[7] Brücher, J., Öman, C. \& Bergström, L. Sorption of halogenated hydrocarbons to colloidal organic material in a landfill leachate (Paper IV). The influence of sorption on transport of organic compounds in soil. J. Brücher, Doctoral thesis, Div. of Water Quality Management, Dept. of Soil Sciences, SLU: Uppsala, Sweden, 1999.

[8] Öman, C. \& Rosqvist, H. Transport of organic compounds with percolating water through landfills. (Paper IV). Emissions of organic compounds from landfills. C. Öman, Doctoral thesis, Div. of Land and Water Resources, Dept. of Civil and Environmental Engineering, KTH Royal Institute of Technology (AFR Report 193, IVL Report A 118 1): Stockholm, Sweden, 1998.

[9] Bozkurt, S., Moreno, L. \& Neretnieks I. Long-term processes in waste deposits. The Science of the Total Environment, 250, pp. 101-121, 2000.

DOI: https://doi.org/10.1016/S0048-9697(00)00370-3

[10] Mårtensson, A., Wahlberg O., Aulin C. \& Ågren, S. The effect of humic substances on the mobility of toxic metals in a mature landfill. Waste Management and Research, 17, pp. 296-304, 1999.

DOI: https://doi.org/10.1034/j.1399-3070.1999.00053.x

[11] Östman, M., Wahlberg, O., Ågren, S., \& Mårtensson, A. Metal and organic matter contents in a combined household and industrial landfill. Submitted for publication to Waste Management and Research, 2003.

[12] Avfallsanläggningar med deponering. Statistik 2001 (Waste plants with landfilling. Statistics 2001; only in Swedish). RVF Rapport 02:14: Malmö, 2002.

[13] European Union, Council Directive 1999/31/EC of 26 April 1999 on the landfilling of waste. Official Journal of European Communities, L 182/1-19, pp. 1-19, 1999.

[14] Leikam, K. \& Stegmann, R. Mechanical-biological pre-treatment of residual municipal solid waste and the landfill behaviour of pre-treated waste (Vol. I). Proc. of the $6^{\text {th }}$ Int. Landfill Symposium in Sardinia, eds. T.M. Christensen, R. Cossu \& R. Stegmann, CISA: Cagliari, Italy, pp. 463-474, 1997. 
KALMAR ECO-TECH'03

Bioremediation and Leachate Treatment

KALMAR, SWEDEN, November 25-27, 2003

[15] Kouzeli-Katsiri, A., Christoulas, D. \& Bosdogianni, A. Leachate degradation after recirculation (Vol. I). Proc. of the $4^{\text {th }}$ Int. Landfill Symposium in Sardinia, eds. T.M. Christensen, R. Cossu \& R. Stegmann, CISA: Cagliari, Italy, pp. 1007-1018, 1993e

[16] Karnik, M. \& Parry, C. Cost implications of operating landfills as flushing bioreactors (Vol. I). Proc. of the $6^{\text {th }}$ Int. Landfill Symposium in Sardinia, eds. T.M. Christensen, R. Cossu \& R. Stegmann, CISA: Cagliari, Italy, pp. 419-425, 1997.

[17] Walker, A.N., Beaven, R.P. \& Powrie, W. Overcoming problems in the development of a high rate flushing bioreactor landfill (Vol. I). Proc. of the $6^{\text {th }}$ Int. Landfill Symposium in Sardinia, eds. T.M. Christensen, R. Cossu \& R. Stegmann, CISAe Cagliari, Italy, pp. 397-408, 1997.

[18] Catalani, S. \& Cossu, R. Flushing of mechanical-biological and thermal pretreated waste. Lab scale tests (Vol. I). Proc. of the $7^{\text {th }}$ Int. Landfill Symposium in Sardinia, eds. T.M. Christensen, R. Cossu \& R. Stegmann, CISA: Cagliari, Italy, pp. 345$352,1999$.

[19] Ritzkowski, M., Heyer, K-U. \& Stegmann, R. Aerobic in situ stabilization of old landfills with the old landfill in Kuhstedt (Germany) serving as an example (Vol. IV). Proc. of the $8^{\text {th }}$ Int. Landfill Symposium in Sardinia, eds. T.M. Christensen, R. Cossu \& R. Stegmann, CISA: Cagliari, Italy, pp. 577-586, 2001.

[20] Leikam, K., Heyer, K.-U. \& Stegmann, R. Aerobic in-situ stabilisation of completed landfills and old sites. Proc. of the $3^{\text {rd }}$ Swedish Landifill Research Symposium, ed. Anders Lagerkvist, Avfallsforskningsrådet (AFR Report 210): Stockholm, pp. 91-92, $1998 \mathrm{e}$

[21] Bozkurt, S., Sifvert, M., Moreno, L. \& Neretnieks I. The long-term evolution of and transport processes in a self-sustained final cover on waste deposits. The Science of the Total Environment, 271 (1-3), pp. 145-168, 2001.

[22] Göschl, R. Remediation of disused landfill sites through excavation, redeposition and treatment (Vol. IV). Proc. of the $7^{\text {th }}$ Int. Landfill Symposium in Sardinia, eds. T.M. Christensen, R. Cossu \& R. Stegmann, CISA: Cagliari, Italy, pp. 579-586, 1999.

[23] Geusebroek, H.L.J. Complete removal of two landfills in Veenendaal (Vol. IV). Proc. of the $8^{\text {th }}$ Int. Landfill Symposium in Sardinia, eds. T.M. Christensen, R. Cossu \& R. Stegmann, CISA: Cagliari, Italy, pp. 561-566, 2001.

[24] Molander, L. Förslag till ramprogram för lakvatten (Proposal for a frame programme regarding leachate; only in Swedish). RVF Rapport 02:04, RVF:s utvecklingssatsning för deponering, 2002.

[25] Cossu, R., Casu, G., Lavagnolo, M.C. \& Andreottola, G. Biological removal of nutrients in co-treatment of leachate and sewage. (Vol. I). Proc. of the $4^{\text {th }}$ Int. Landfill Symposium in Sardinia, eds. T.M. Christensen, R. Cossu \& R. Stegmann, CISA: Cagliari, Italy, pp. 893-905, 1993e 
KALMAR ECO-TECH'03

Bioremediation and Leachate Treatment

KALMAR, SWEDEN, November 25-27, 2003

[26] Hasselgren, K. Utnyttjande av kommunala restprodukter i Salix-odling (Recycling of municipal waste products in Salix plantations; only in Swedish). Sveriges Utsädesförenings Tidskrift (Journal of the Swedish Seed Association), 2, pp. 73-83, 2001.

[27] Dimitriou, I., Aronsson, P. \& Weih, M. Stress tolerance of five willow clones after irrigation with different amounts of landfill leachate. Submitted to Bioresource Technology, 2003.

[28] Bergström, R. \& Ek, M. Lakvattenbehandling med biologi och omvänd osmos (Leachate treatment making use of biology and reverse osmosis; only in Swedish). Nonofficial report, IVL Swedish Environmental Research Institute, 1995. 